\title{
ПРИЧИНЫ ВЫСОКОГО СОПРОТИВЛЕНИЯ ПОЛЗУЧЕСТИ СОВРЕМЕННЫХ ВЫСОКОХРОМИСТЫХ СТАЛЕЙ МАРТЕНСИТНОГО КЛАССА
}

\author{
(C) 2015 г. В. А. Дудко, А. Н. Беляков, Р. О. Кайбышев \\ Представлено академиком РАН В.М. Счастливцевым 25.12.2014 г.
}

Поступило 26.03.2015 г.

\begin{abstract}
В работе обсуждены причины высокой жаропрочности мартенситных сталей с $9 \% \mathrm{Cr}$ на основании результатов исследования эволюции дислокационной структуры мартенсита в стали 10Х9В2МФБР в процессе ползучести при $650^{\circ} \mathrm{C}$. Структура стали после отпуска характеризовалась значительными упругими микродеформациями кристаллической решетки, источником которых были дислокации с одинаковым знаком и дальнодействующие напряжения от дисклокационных границ реек. Повышенное сопротивление ползучести в жаропрочных сталях, содержащих 9\% $\mathrm{Cr}$, достигается благодаря действию как пороговых напряжений от карбонитридов $\mathrm{M}(\mathrm{C}, \mathrm{N})$, так и от внутренних упругих напряжений.
\end{abstract}

DOI: $10.7868 / \mathrm{S} 0869565215250131$

Уникально высокая жаропрочность современных высокохромистых сталей мартенситного класса типа 10Х9В2МФБР при температурах до $650^{\circ} \mathrm{C}$ достигается комплексным легированием, которое обеспечивает устойчивость дислокационной структуры мартенсита при отпуске и ползучести благодаря твердорастворному и дисперсионному упрочнению $[1,2]$. При отпуске в ферритной матрице сталей этого типа однородно выделяются карбонитриды $\mathrm{M}(\mathrm{C}, \mathrm{N})$, а по границам реек, пакетов и бывших аустенитных зерен карбиды $\mathrm{M}_{23} \mathrm{C}_{6}$ [1-3]. Именно введение карбонитридов размером от 10 до 30 нм в стали мартенситного класса с 9\% Сr и $1 \%$ Мо позволило повысить температуру их эксплуатации на $100^{\circ} \mathrm{C}$ [2]. До настоящего времени считали [2, 3], что уникально высокая жаропрочность связана с тем, что карбонитриды подавляют миграцию границ реек. Однако в работе [1] было установлено, что наибольший вклад в суммарную силу, тормозящую миграцию границ, вносят зернограничные карбиды, тогда как зинеровская сила торможения от частиц $\mathrm{M}(\mathrm{C}, \mathrm{N})$ в несколько раз меньше. Соответственно подавление миграции границ реек за счет зернограничных частиц не может быть причиной рекордной жаропрочности стали 10Х9В2МФБР, поскольку их удельный объем такой же, как в стали Р9 (0.1 мас. \%С-9Cr-1Мо), которая может экс-

Белгородский государственный национальный исследовательский университет

E-mail:dudko@bsu.edu.ru плуатироваться только до $520^{\circ} \mathrm{C}$ [2]. Цель настоящей работы - установить роль карбонитридов в ползучести стали 10Х9В2МФБР.

В работе впервые показано, что высокая жаропрочность сталей мартенситного класса типа 10Х9В2МФБР обусловлена тем, что наноразмерные частицы $\mathrm{M}(\mathrm{C}, \mathrm{N})$ эффективно тормозят движение дислокаций при ползучести и предотвращают трансформацию дислокационных границ реек, которые являются источниками дальнодействующих полей упругих напряжений, в субзеренные границы. Таким образом, торможение дислокаций при ползучести обеспечивается одновременным действием двух механизмов, связанных с взаимодействием движущихся дислокаций с дисперсными частицами и полями упругих напряжений. До настоящей работы ни в одном материале не наблюдали одновременного действия двух механизмов пороговых напряжений. Именно высокие пороговые напряжения обеспечивают уникальное сопротивление ползучести сталей типа 10Х9В2МФБР. Представленный анализ существенно расширяет современные представления о физических механизмах прочности теплотехнических сталей.

В работе была исследована сталь 10Х9В2МФБР (Fe-0.1 мас. \%C-0.17Si-0.54Mn-8.75Cr-0.21Ni$0.51 \mathrm{Mo}-1.60 \mathrm{~W}-0.23 \mathrm{~V}-0.07 \mathrm{Nb})$. Термическая обработка состояла из нормализации от $1050 \pm 10^{\circ} \mathrm{C}$ и последующего отпуска в течение 3 ч при $720 \pm$ $\pm 10^{\circ} \mathrm{C}$. Детали методик испытаний на ползучесть и микроструктурных исследований описаны в работах $[1,4,5]$. 
Таблица 1. Параметры микроструктуры стали 10Х9В2МФБР после отпуска при $720^{\circ} \mathrm{C}$ и после ползучести при $650^{\circ} \mathrm{C}$ до различных степеней деформации

\begin{tabular}{|c|c|c|c|c|c|}
\hline \multirow{2}{*}{ Фаза, параметр } & \multirow{2}{*}{ Отпуск } & \multicolumn{4}{|c|}{ Степень деформации } \\
\hline & & $1 \%$ & $4 \%$ & $8 \%$ & $18 \%$ \\
\hline \multicolumn{6}{|l|}{ Фаза Лавеса: } \\
\hline размер, нм & - & $215 \pm 32$ & $286 \pm 43$ & $313 \pm 47$ & $303 \pm 47$ \\
\hline доля, об. \% & - & 1.17 & 1.17 & 1.17 & 1.17 \\
\hline \multicolumn{6}{|l|}{$\mathrm{Me}_{23} \mathrm{C}_{6}$ : } \\
\hline размер, нм & $110 \pm 25$ & $140 \pm 33$ & $169 \pm 39$ & $158 \pm 9$ & $195 \pm 39$ \\
\hline доля, об. \% & 1.79 & 1.79 & 1.79 & 1.79 & 1.79 \\
\hline \multicolumn{6}{|l|}{ MeX: } \\
\hline размер, нм & $31 \pm 15$ & $31 \pm 16$ & $42 \pm 9$ & $36 \pm 8$ & $46 \pm 24$ \\
\hline доля, об. \% & 0.23 & 0.23 & 0.23 & 0.23 & 0.23 \\
\hline Поперечный размер реек (субзерен), нм & $330 \pm 25$ & $330 \pm 25$ & $430 \pm 60$ & $710 \pm 20$ & $740 \pm 50$ \\
\hline Плотность дислокаций, $10^{14} \mathrm{M}^{-2}$ & $6.2 \pm 0.7$ & $3.6 \pm 1.2$ & $2.2 \pm 0.7$ & $1.0 \pm 0.4$ & $1.0 \pm 0.4$ \\
\hline Средняя разориентировка границ реек & 2.7 & 2.6 & 2.1 & 2.3 & 2.7 \\
\hline
\end{tabular}

Параметры микроструктуры после отпуска и различных степеней деформации при $650^{\circ} \mathrm{C}$ и напряжении 118 МПа [1, 4] приведены в табл. 1. Несмотря на постепенный рост поперечного размера реек при ползучести, их средняя разориентировка не изменяется. Следовательно, дислокации, которые захватываются этими границами в процессе ползучести [6], взаимно аннигилируют.

Зависимости скорости деформации от напряжения при $650^{\circ} \mathrm{C}$ показаны на рис. 1 . В интервале

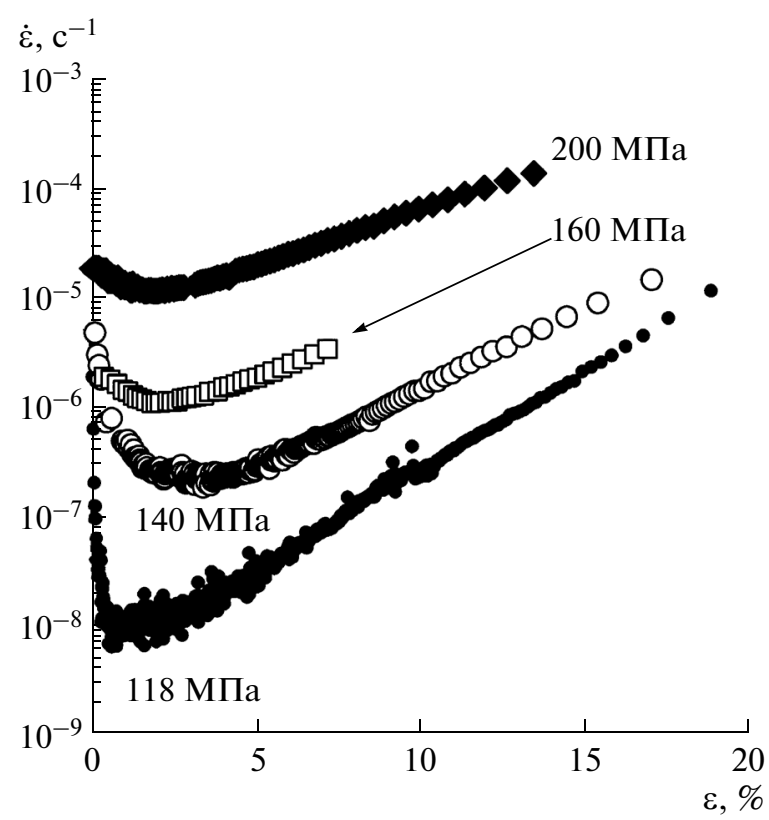

Рис. 1. Зависимость скорости деформации от степени деформации в стали 10Х9В2МФБР при $650^{\circ} \mathrm{C}$. степеней деформации от 1 до 4\% достигается минимальная скорость деформации ( $\left.\dot{\varepsilon}_{\min }\right)$ при всех напряжениях. Анализ зависимости $\dot{\varepsilon}_{\min }$ от приложенного напряжения $(\sigma)$ показал, что она подчиняется степенному закону [2]: $\dot{\varepsilon}_{\min }=A\left(\sigma-\sigma_{t h}\right)^{n}$, где $\sigma_{t h}-$ пороговое напряжение, $n-$ истинный показатель степени при напряжении. Этот закон описывает поведение при ползучести материалов, в которых пороговые напряжения препятствуют движению дислокаций. Рассчитанные величины $n=5.5$ и $\sigma_{t h}=88$ МПа указывают на то, что сталь эксплуатируется в режиме горячей деформации, а ее высокое сопротивление ползучести обеспечивается исключительно присутствием пороговых напряжений. Величина пороговых напряжений несколько больше допустимых напряжений в этой стали для ресурса $10^{5}$ ч, что уникально для жаропрочного материала [2].

Обычно источником пороговых напряжений являются дисперсные частицы. В сталях типа 10Х9В2МФБР карбиды $\mathrm{M}_{23} \mathrm{C}_{6}$ и фаза Лавеса расположены преимущественно по границам и не могут служить препятствием для подвижных дислокаций. Поэтому источником пороговых напряжений могут быть только частицы М(C, N). Величины теоретических пороговых напряжений, рассчитанные по известным моделям [7], приведены в табл. 2 вместе с экспериментально определенными значениями. Однако в высокохромистых сталях мартенситного класса в отличие от других жаропрочных материалов присутствуют внутренние упругие напряжения [2]. Они также могут тормозить движение дислокаций.

Касательные напряжения $\left(\tau_{l a t h}\right)$ внутри отдельных реек, которые связаны с упругим искажени- 
Таблица 2. Пороговые напряжения (МПа), рассчитанные по различным моделям, а также величины внутренних напряжений, определенных различными методами

\begin{tabular}{|c|c|c|c|c|c|c|}
\hline \multirow{2}{*}{$\varepsilon, \%$} & \multirow{2}{*}{$\begin{array}{c}\text { Напряжение } \\
\text { Орована }\end{array}$} & \multirow{2}{*}{$\begin{array}{c}\text { Локальное } \\
\text { переползание }\end{array}$} & \multirow{2}{*}{$\begin{array}{c}\text { Напряжение } \\
\text { отрыва }\end{array}$} & \multicolumn{2}{|c|}{ Внутреннее напряжение } & \multirow{2}{*}{$\begin{array}{c}\text { Экспериментальное } \\
\text { пороговое } \\
\text { напряжение* } \tau_{t h}\end{array}$} \\
\hline & & & & ПЭМ & PCA & \\
\hline 0 & 62 & 19 & 51 & 76 & 66 & - \\
\hline 1 & 62 & 19 & 51 & 49 & 47 & 51 \\
\hline 4 & 62 & 19 & 38 & 43 & 34 & - \\
\hline 8 & 53 & 16 & 44 & 40 & 26 & - \\
\hline 18 & 42 & 13 & 34 & 22 & 22 & - \\
\hline
\end{tabular}

*Приведены касательные напряжения $\tau_{t h}=\sigma_{t h} / \sqrt{3}$.

ем кристаллической решетки, были рассчитаны по уравнению $\tau_{\text {lath }} / G=0.35 t \theta / l_{\tau}$, где $t-$ толщина фольги, $\theta-$ угол разориентировки между двумя точками внутри рейки, определенный методом линий Кикучи в сходящемся электронном пучке на просвечивающем электронном микроскопе (ПЭМ), и $l_{\tau}-$ расстояние между точками внутри рейки, в которых определена ориентировка [8]. Средние величины внутренних напряжений после отпуска и деформации до $1,4,8,18 \%$ при $650^{\circ} \mathrm{C}$ и начальном напряжении 118 МПа приведены на рис. 2 вместе с напряжениями, определенными методом рентгеноструктурного анализа (PCA).

Главным источником внутренних напряжений служат отдельные дислокации внутри реек и дислокационные границы реек. При ползучести происходит перестройка дислокаций в границах реек, что приводит к их трансформации в совершенные субзеренные границы, которые имеют низкие дальнодействующие напряжения или не имеют их совсем. Эта трансформация объясняет неизменность их разориентировки с увеличением степени деформации. Одновременно взаимная аннигиляция решеточных дислокаций с противоположными векторами Бюргерса уменьшает их плотность (табл. 1). Развитие этих двух процессов приводит $\mathrm{K}$ уменьшению дальнодействующих упругих напряжений (рис. 2). Карбонитриды $\mathrm{M}(\mathrm{C}, \mathrm{N})$, блокируя движение дислокаций внутри реек и их перераспределение в границах реек, препятствуют этой трансформации, в то время как зернограничные частицы $\mathrm{M}_{23} \mathrm{C}_{6}$ и фаза Лавеса могут только сдерживать миграцию субзеренных границ и замедлять перестройку границ реек в субзеренные границы.

Таким образом, главной причиной высокой жаропрочности являются пороговые напряжения, связанные как с наличием в структуре стали карбонитридов $\mathrm{M}(\mathrm{C}, \mathrm{N})$, так и с внутренними упругими напряжениями. Величины напряжений отрыва и внутренних напряжений, измеренных методами РСА и ПЭМ, близки к пороговым на- пряжениям $\tau_{t h}$ (табл. 2). Вероятно, действия напряжений этих двух типов торможения движущихся дислокаций происходят параллельно, внося совместный вклад в жаропрочность. Стали мартенситного класса могут сопротивляться ползучести до тех пор, пока карбонитриды $\mathrm{M}(\mathrm{C}, \mathrm{N})$ тормозят движение дислокаций и соответственно препятствуют релаксации внутренних напряжений из-за перестройки дислокаций в границах реек и уменьшения плотности решеточных дислокаций.

Авторы выражают благодарность центру коллективного пользования "Диагностика структуры и свойств наноматериалов" НИУ БелГУ за оборудование, предоставленное для проведения структурных исследований.

Исследование поддержано грантом Российского научного фонда (проект 14-29-00173).

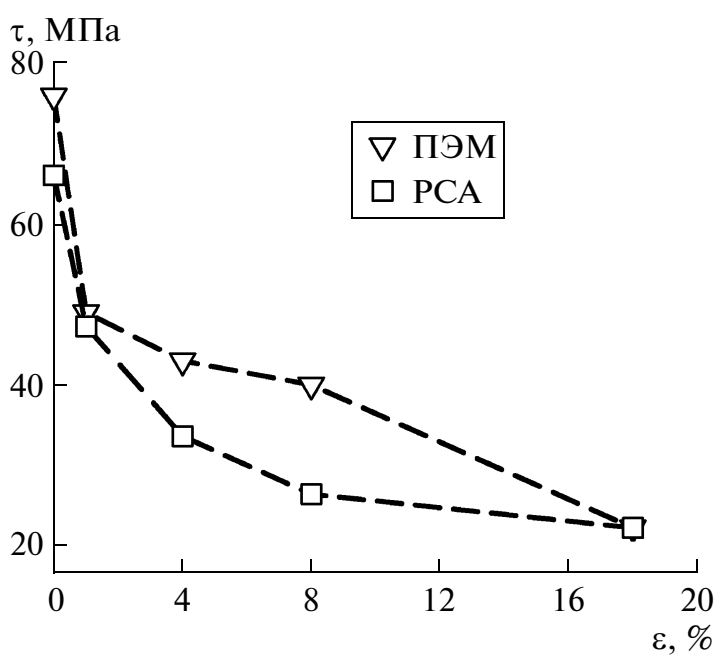

Рис. 2. Зависимость внутренних напряжений от степени деформации. 


\section{СПИСОК ЛИТЕРАТУРЫ}

1. Dudko V., Belyakov A., Molodov D., Kaibyshev $R$. Microstructure Evolution and Pinning of Boundaries by Precipitates in a 9 pct. Cr Heat Resistant Steel During Creep // Metal. Mat. Trans. A. 2013. V. 44. P. 162172.

2. Кайбышев Р.О., Скоробогатых В.Н., Щенкова И.А. Новые стали мартенситного класса для тепловой энергетики. Жаропрочные свойства // ФММ. 2009. T. 108. № 5. C. 1-15.

3. Kostka A., Tak K.-G., Hellmig R.J., Estrin Y., Eggeler G. On the Contribution of Carbides and Micrograin Boundaries to the Creep Strength of Tempered Martensite Ferritic Steels // Acta mater. 2007. V. 55. P. 539550 .
4. Дудко В.А., Беляков А.Н., Скоробогатых В.Н., Кайбымев P.O. Структурные изменения в жаропрочной стали 10Х9В2МФБР в процессе ползучести при $650^{\circ} \mathrm{C} / /$ МиТОМ. 2010. № 3 (657). С. 26-32.

5. Zaefferer $S$. Computer-Aided Crystallographic Analysis in the TEM // Adv. Imaging and Electron Phys. 2002. V. 125. P. 355-415.

6. Pantleon $W$. On the Statistical Origin of Disorientations in Dislocation Structures // Acta mater. 1998. V. 46. P. 451-456.

7. Mohamed F.A., Park K.-T., Lavernia E.J. Creep Behaviour of Discontinuous SiC-Al Composites // Mater. Sci. Eng. A. 1992. V. 150. P. 21-35.

8. Belyakov A., Tsuzaki K., Kimura Y., Mishima Y. Tensile Behaviour of Submicrocrystalline Ferritic Steel Processed by Large-Strain Deformation // Phil. Mag. Lett. 2009. V. 89. P. 201-212. 